\title{
Information and Communication Technology Leadership of School Administrators in Thailand
}

\author{
Amnat Apsorn \\ King Mongkut's Institute of Technology Ladkrabang, Bangkok, Thailand, \\ amnat_com@sstb.ac.th
}

\section{Boonchan Sisan}

King Mongkut's Institute of Technology Ladkrabang, Bangkok, Thailand

\section{Pariyaporn Tungkunanan}

King Mongkut's Institute of Technology Ladkrabang, Bangkok, Thailand

This research aims to study the components and to do confirmatory factor analysis, and study the perceptions of ICT leadership of school administrators in Thailand. The results indicate that eight components of information and communication technology (ICT) leadership: developing a vision and administrative plans for the use of ICT in schools, establishing strategies for promoting teachers' and students' use of technology in instruction; developing plans for improving teachers' and supporting staff's technological skills; managing, supporting and facilitating an atmosphere conducive to the use of ICT and providing information technology (IT) resources; learning about meeting ICTrelated challenges with prudence and care; acting as a role model in applying ICT to daily personal and professional matters; sharing knowledge, opening up opportunities and creating an ICT culture in schools in order to develop a learning community, and overseeing and doing follow-up on data storage and data updates for the benefit of decision making and problem solving. Confirmatory Factor Analysis suggests that the components of IT and communication leadership correspond significantly with empirical data and school administrators' perceptions of ICT leadership for use to develop guidelines for efficiently and effectively improving the capacity of ICT school leaders.

Keywords: components, leadership, ICT, school administrators, confirmatory factor analysis

\section{INTRODUCTION}

Globalization and information and communication technology (ICT) breakthroughs have led to modernization in economies and organizational competitiveness (Haughey,

Citation: Apsorn, A., Sisan, B., \& Tungkunanan, P. (2019). Information and Communication Technology Leadership of School Administrators in Thailand. International Journal of Instruction, 12(2), 639-650. https://doi.org/10.29333/iji.2019.12240a 
2006). With regard to the role of ICT in education, a number of countries across the globe, both developed and underdeveloped, have invested considerably in ICT to enhance education (Sultan Albugami \& Vian Ahmed, 2015). As learners and users of ICT, school directors are models in recognizing the importance of ICT among school communities. The form and role of ICT are important for improving a school's learning culture (Cusack, Gurr \& Schiller 1999, Day Harris \& Hadfield 2001, Gurr, 2000, Gurr, Drysdale \& Mulford, 2006, Hately \& Schiller 2003, Otto \& Albion 2002, Schiller, 2002, Sweeney, 2005). ICT is critically important for creating quality data, and managing data is essential for effective decision making (Ayeni, 2004) and aiding school administrators in managing schools' curricula and instruction, as well as maintaining relationships between school communities and school administration (Nwosu, 2003). In this light, ICT leaders serve as exemplars for others in regards to ICT use. They are the most appropriate candidates for anticipating others' expectations, while showing a high degree of professionalism.

School administrators are organizational leaders who are a key driving factor in using ICT in schools. As such, they need to understand the capabilities of modern technology in order to make personal use of it and foster a school's culture of exploring new techniques for instruction, learning, and management (Anantha Raj A. Arokiasamya, Abdul Ghani Kanesan bin Abdullahb \& Aziah Ismailc, 2015). School leaders are those who develop a vision and who are inspiring. They can improve their competencies just as others can (Gurr, Drysdale \& Mulford, 2006). They also have a teacher's vision of the possibilities for applying ICT to their instruction and should support and enhance the skills of others. In assuming an effective supervisory role, school leaders are deeply involved in using ICT. To fulfill their vision, school leaders must exert power in using ICT, but as ICT learners, they have less sophisticated ability and understanding than their vision (Gurr, 2000). Bishop (2002) stated that some school leaders have been informed at least about ICT use among their school staff; however, Gurr (2000) noted that modern teachers have a more fundamental understanding of using ICT in performing their functions.

Hope, Kelly \& Guyden (2000) held that technology leadership deals primarily with making sense of technology and the ways of applying it to accomplishing tasks. Gibson (2002) stated that school leaders need to concentrate on designing curricula, managing resources, addressing problems with personnel, facilitating communication, and providing support in order to improve human resources and work. This requires school leaders to understand the capacity of new technology so that they can employ it individually and promote a school culture of exploring innovative techniques in instruction, learning, and management (Schiller, 2003).

Even though school leaders can be effective models in using and determining ICT directions for school teachers and staff, school administrators are not necessarily experts in the use of ICT (Haughey, 2006). These administrators can rely on school staff in order to facilitate the use of ICT and set directions of ICT use in schools. It is thus reasonable that school supervisors need to ask for help with making decisions about ICT (Gurr 2000). Hately \& Schiller (2003) pointed out that there must be an ICT leader who 
can support teachers, but that leader does not necessarily have to be a school leader. School leaders who attempt to be an ICT leader but who do not realize their own abilities regarding ICT will not effectively achieve the goal of enhancing ICT in their organization (Lee, Gaffney \& Schiller 2001).

Lee, Gaffney \& Schiller (2001) identified the qualities of ICT leaders as: understanding education of quality in global networking, gaining insights into ICT with respect to learning and teaching, assessing the effectiveness of integrating technical and human resources, being able to work within networking paradigms, appreciating the importance of knowledge management, being an excellent net worker, possessing a high level of analytical skills, having good skills in communication and management, being able to supervise the work of other IT staff, being able to lead the process of change management, being able to educate all students in a digital world, and being able to work as an assistant or deputy leader.

School leaders' leadership predominantly concerns the use of technology aimed at teaching and learning in school, especially their role in managing ICT for instruction, learning, and other aspects related to ICT. Additionally, it has been found that ICT leadership is particularly vital for teachers to implement and foster innovations attached to ICT (Geir, 2013). A school leader is both a leader of change in enhancing school technology and an expert in technology leadership (Januszewski \& Molenda, 2008).

It is essential that school administrators provide leadership in technological use. This can ensure that improving ICT will be beneficial and sustainable for the education provided. School directors serve as successful leaders in technology and should be determined to improve teachers' competency in ICT on an ongoing basis. Furthermore, school leaders formulate policies and should design profession-enhancing programs that aim to develop skills for effectively using technology among school administrators (Mei Wei, Leong; Yan Piaw, Chua \& Kannan, Sathiamoorthy, 2017).

Today we have to rely on ICT. The information technology allows us to increase the ability to calculate and process data, accurately and also to collect a lot of data. The communication network makes it easy to communicate with each other. Causing rapid social change, new society has to rely on ICT. Thai education, administrators lack of the readiness to use information technology to create media, innovation and information technology to develop learners Therefore, the researcher would like to study these the matter, administrators still lack the readiness to use the media create innovative media and information technology. The problems of educational technology, most of which are administrators' readiness problems. Administrators still lack of the readiness in learning technology and do not see the importance of innovation and information technology. Administrators lack of knowledge, lack of experience and expertise in using media to create innovative media and information technology or various elements for teaching and learning.

Most school administrators in Thailand still lack the qualities of ICT leadership, which is a major problem affecting educational administration and management in the level of schools and overall education. It is inevitable that school administrators will have a 
unique and increasing role in the use of ICT (Akbaba-Altun, 2004). After a review of the literature, researchers are interested in examining the ICT leadership of school leaders affiliated with the Office of the Basic Education Commission in order to develop guidelines for efficiently and effectively improving the capacity of ICT school leaders.

\section{Objective of the Study}

To study the components and to do Confirmatory Factor Analysis (CFA) that aims to test the theory, identify components and variables, and study the perceptions of ICT leadership of school administrators.

\section{Conceptual Framework}

The concepts of this present study consist of those of the components of ICT leadership of school leaders affiliated with the Office of the Basic Education Commission. I have studied the findings of Yee (2000), David (2011), Schiller (2000), Kunsoo (2013), Avery (2014), Mark (2007), DuFour, Eaker \& Many (2006), and Kathryn (2005).

\section{METHOD}

The population used in the study includes a total of 780 school directors, deputy school directors, heads of departments, and heads of supporting sections in 52 schools belonging to Secondary Educational Service Area Office 2 under the Office of the Basic Education Commission, Ministry of Education. The sample size was determined follow by Hair, Black, Bain, Anderson \& Tatham (2010) stated that in terms of analyzing the components, researchers generally use a sample size 5-20 times larger than the number of observed variables. In this present study, there are 20 observed variables, thus allowing for a total sample size ranging from $105-420$. Therefore, the researchers set a sample of 425 participants and used stratified random sampling. The instrument use for collection was a Linkert-scale questionnaire sent to participants by email and postage. $425(100 \%)$ questionnaires were complete and returned. Items concerning the behaviors of information and communication technology leadership of school administrators based on the concepts of Yee (2000), David (2011), Schiller (2000), Kunsoo (2013), Avery (2014), Mark (2007), DuFour, Eaker \& Many (2006), and Kathryn (2005) with a rating scale of 5 levels: most(5),much(4), moderate(3), little(2), and least(1). For the item objective congruence of $0.60-1.00$, and discriminative power between .70-.94 and the analysis, Cronbach's method was utilized, with the coefficient value equal reliability between .91 to .97 .

The results were analyzed by means of Confirmatory Factor Analysis (CFA). LISREL was used to perform the CFA of the information and communication technology leadership questionnaire analyzing the fit of models and its respective parameter estimates. CFA is a multivariate analysis used to test concepts based on multiple measured indicators (Tabachnick \& Fidell, 2007). One of the advantages of CFA is its flexibility when applied to a complex hypothetical model. Estimation methods used in Confirmatory Factor Analysis involve a maximum likelihood factor that can determine the optimal value of the factor loading. A valid indicator is said to be convergent if the loading value on standard regression weight is greater than .5 or $\mathrm{p}<\alpha=.05$, the chi- 
squared $(\chi 2)$ value is small, the significance probability is greater than $.05(\mathrm{p}>.05)$, and RMSEA is less than .05. (Jöreskog \& Sörbom, 1999). The perceptions of ICT were analyzed by SPSS.

\section{FINDINGS}

\section{Components of ICT Leadership}

In terms of the the components of ICT leadership among school administrators working under the Office of the Basic Education Commission, the researchers studied research findings of Yee (2000), David (2011), Schiller (2000), Kunsoo (2013), Avery (2014), Mark (2007), DuFour, Eaker \& Many (2006), and Kathryn (2005) as displayed in Table 1.

\section{Table 1}

Data Synthesis for Formulating the Components of ICT Leadership of School Administrators

\begin{tabular}{ll}
\hline Components & \multicolumn{1}{c}{ Sources } \\
\hline $\begin{array}{l}\text { Equity, determination to develop a vision, learning challenges, } \\
\text { giving knowledge with patience, saving organizations, }\end{array}$ & Yee (2000); David (2011) \\
continually supervising work, managing networks, \\
implementing changes in a careful fashion, fostering technology \\
culture by encouraging teachers and school staff to participate \\
in such culture.
\end{tabular}


Table 1 shows research findings and analyses of the concepts of ICT leadership qualities. Following the synthesis of the data above, the researchers determined the components of ICT leadership displayed below:

1. Establishing a vision and school operational guidelines;

2. Implementing strategies and providing support for teachers and students to use technology for their instruction and learning;

3. Developing plans for improving teachers' and staff's skills about how to work effectively with technology;

4. Managing, supporting, and facilitating the creation of a proper atmosphere, allocating resources related to IT;

5. Studying challenges carefully;

6. Serving as exemplars in daily application of ICT both to personal matters and professional areas;

7. Sharing knowledge, providing opportunities and ingraining an ICT-related culture into school teachers and school staff, thus resulting in learning communities;

8. Supervising and doing follow-up on storing and updating data which can help decide how to address problems that may arise.

Variable codes were created to analyze the components. The first variable code was VOP, which encompasses setting a vision and guidelines for school work using ICT. Secondly, establishing strategies and supporting teachers' and students' use of technology in instruction and learning was encoded SSP. Thirdly, setting plans for improving teachers' and staff's skill in effectively using technology was encoded PIT. Fourthly, managing, supporting and facilitating the creation of a proper atmosphere and allocating technological resources is named AIS. The fifth code concerns studying challenges with care. Sixthly, behaving as models in applying ICT to daily use, whether this concerns personal or professional matters, was encoded CLS. Seventhly, sharing knowledge, creating opportunities and an ICT culture among teachers and staff in order to build learning communities is named PRM. Finally, supervising and doing follow-ups on storing and updating data in a reliable way for deciding how to tackle problems is called COD.

\section{Confirmatory Factor Analysis}

Confirmatory Factor Analysis (CFA) was conducted to test theories and identify the components.

The data of means, standard deviation, and coefficient of variation and results of factor construct validity analysis revealed 8 components, which corresponds to empirical data, as shown in Table 2. 
Table 2

Goodness-of-Fit Index

\begin{tabular}{ll}
\hline \multicolumn{1}{c}{ Components } & \multicolumn{1}{c}{ Fit Index } \\
\hline VOP & $\chi^{2}=3.39, \mathrm{df}=4, \mathrm{p}$-value $=0.50$, RMSEA $=0.000$ \\
\hline SSP & $\chi^{2}=7.19, \mathrm{df}=9, \mathrm{p}$-value $=0.61$, RMSEA $=0.000$ \\
\hline PIT & $\chi^{2}=3.34, \mathrm{df}=7, \mathrm{p}$-value $=0.85$, RMSEA $=0.000$ \\
\hline AIS & $\chi^{2}=9.76, \mathrm{df}=11, \mathrm{p}$-value $=0.55$, RMSEA $=0.000$ \\
\hline CLS & $\chi^{2}=6.97, \mathrm{df}=5, \mathrm{p}$-value $=0.22$, RMSEA $=0.031$ \\
\hline PRM & $\chi^{2}=19.58, \mathrm{df}=16, \mathrm{p}$-value $=0.24$, RMSEA $=0.023$ \\
\hline COD & $\chi^{2}=6.47, \mathrm{df}=6, \mathrm{p}$-value $=0.37$, RMSEA $=0.014$ \\
\hline MDC & $\chi^{2}=7.15, \mathrm{df}=8, \mathrm{p}$-value $=0.52$, RMSEA $=0.000$ \\
\hline
\end{tabular}

The results of CFA to test the theories and identify the components were used to create a questionnaire that explores the perceptions of ICT leadership among school administrators.

\section{The Perceptions of ICT Leadership}

It was found that the majority of questionnaire respondents were $66.4 \%$ heads of sections, followed by heads of departments, school deputy directors, and school directors. This is illustrated in Table 3, which shows that school administrators perceive VOP, or the establishment of visions and guidelines for schools' operating procedures for ICT as being the most important component. However, CLS or the perception of serving as examples of applying ICT to daily life, including both in personal and professional life, was considered the least important. This is displayed in Table 4.

Table 3

Frequency and Percentage of Questionnaire Respondents

\begin{tabular}{lll}
\hline General information & Frequency & percentage \\
\hline School directors & 36 & 8.5 \\
\hline School deputy directors & 35 & 8.2 \\
\hline Heads of academic departments & 72 & 16.9 \\
\hline Heads of supporting sections & 282 & 66.4 \\
\hline Total & 425 & 100.0 \\
\hline
\end{tabular}

Table 4

Descriptive Statistics on the Perception of ICT Leadership

\begin{tabular}{lccl}
\hline Components & Mean & Std. Deviation & Meaning of results \\
\hline VOP & 3.8146 & .34624 & high \\
\hline SSP & 3.7908 & .36696 & high \\
\hline PIT & 3.7733 & .38233 & high \\
\hline AIS & 3.8085 & .36503 & high \\
\hline CLS & 3.7630 & .39960 & high \\
\hline PRM & 3.8235 & .36961 & high \\
\hline COD & 3.8082 & .38181 & high \\
\hline MDC & 3.7916 & .38650 & high \\
\hline
\end{tabular}


An analysis of variance of the components that aims to compare and contrast the perceptions of ICT leadership according to the job positions of the respondents revealed that school administrators, who include school directors, deputy school directors, heads of academic departments, and heads of supporting sections, had a statistically significant perceptions at $.05(\mathrm{p}<.05)$ in the following components: 1) establishing visions and guidelines for schools' ICT operating procedures (VOP), 2) determining strategies and providing support to teachers and students with respect to applying technology to instruction and learning (SSP), 3) issuing plans for improving teachers' and staff's skills that allow them to work effectively with technology (PIT), 4) managing, supporting, and facilitating the creation of an appropriate atmosphere, and allocating resources related to information technology (AIS), 5) studying challenges with care, 6) acting as role models of applying ICT to daily life in terms of personal and professional aspects (CLS), and 7) sharing knowledge, creating opportunities and ingraining culture (PRM) of ICT into school teachers and school staff, producing a learning atmosphere (COD). This is illustrated in Table 5.

Table 5

Comparison of Variance of Perceiving ICT Leadership

\begin{tabular}{|c|c|c|c|c|c|c|}
\hline & & Sum of Squares & df & Mean Square & $\mathrm{F}$ & Sig. \\
\hline \multirow[t]{3}{*}{ VOP } & Between Groups & 1.751 & 3 & .584 & 5.006 & $.002 *$ \\
\hline & Within Groups & 49.079 & 421 & .117 & & \\
\hline & Total & 50.830 & 424 & & & \\
\hline \multirow[t]{3}{*}{ SSP } & Between Groups & 1.920 & 3 & .640 & 4.882 & $.002 *$ \\
\hline & Within Groups & 55.175 & 421 & .131 & & \\
\hline & Total & 57.094 & 424 & & & \\
\hline \multirow[t]{3}{*}{ PIT } & Between Groups & 2.238 & 3 & .746 & 5.257 & $.001^{*}$ \\
\hline & Within Groups & 59.741 & 421 & .142 & & \\
\hline & Total & 61.979 & 424 & & & \\
\hline \multirow[t]{3}{*}{ AIS } & Between Groups & 2.095 & 3 & .698 & 5.404 & $.001^{*}$ \\
\hline & Within Groups & 54.402 & 421 & .129 & & \\
\hline & Total & 56.497 & 424 & & & \\
\hline \multirow[t]{3}{*}{ CLS } & Between Groups & 2.359 & 3 & .786 & 5.065 & $.002 *$ \\
\hline & Within Groups & 65.346 & 421 & .155 & & \\
\hline & Total & 67.705 & 424 & & & \\
\hline \multirow[t]{3}{*}{ PRM } & Between Groups & 2.014 & 3 & .671 & 5.055 & $.002 *$ \\
\hline & Within Groups & 55.911 & 421 & .133 & & \\
\hline & Total & 57.925 & 424 & & & \\
\hline \multirow[t]{3}{*}{ COD } & Between Groups & 1.761 & 3 & .587 & 4.115 & $.007 *$ \\
\hline & Within Groups & 60.048 & 421 & .143 & & \\
\hline & Total & 61.809 & 424 & & & \\
\hline \multirow[t]{3}{*}{ MDC } & Between Groups & 1.015 & 3 & .338 & 2.285 & .078 \\
\hline & Within Groups & 62.323 & 421 & .148 & & \\
\hline & Total & 63.337 & 424 & & & \\
\hline
\end{tabular}

$* \mathrm{p}<.05$. 


\section{DISCUSSION AND CONCLUSION}

A study of ICT leadership of school administrators in Thailand was conducted and reveals eight ICT components: 1) establishing visions and guidelines for school work related to ICT (Yee, 2000), 2) setting strategies and providing teachers and students with technological support to be used in instruction and learning (Schiller , 2000; Kunsoo, 2013), 3) developing plans for enhancing teachers' and staff's skills that allow them to effectively work with technology (Kunsoo, 2013; Avery, 2014), 4) managing, supporting, and facilitating the production of an appropriate atmosphere and allocating information technology resources (Avery, 2014; Schiller, 2000), 5) studying challenges with prudence (Yee, 2000), 6) serving as role models in applying ICT to personal matters and work issues in daily life (Mark, 2007), 7) sharing knowledge, providing opportunities and establishing a culture of ICT for teachers and staff with a view to fostering learning communities (Yee, 2000; Mark, 2007), and 8) supervising and doing follow-ups on storing and updating data in a reliable way to be used to make decisions about solving problems (Kathryn, 2005). ICT leadership helps administrators make decisions on organizational policies and activities for facilitating the effective use of ICT in education (Anderson \& Dexter, 2005). As leaders in the use of modern technology, administrators should work to satisfy the needs for continuous educational changes. To achieve this expectation, school leaders should establish a vision for training teachers and staff, set priorities, allocate resources among teachers and staff, give advice on organizing schools, and present guidelines for the use of educationally efficient technology to stakeholders in the educational field. In this light, studies that have been conducted in the United States and Canada are the leading research that can determine the standards of technology leadership among school administrators, along with regular and progressive breakthroughs of IT (Yee, 2000; Redish \& Chan, 2007).

The results of the confirmatory factor analysis of the information and communication technology leadership indicate that the sustainable leadership model is consistent with empirical data: $\operatorname{VOP}\left(\chi^{2}=3.39, \mathrm{df}=4, \mathrm{p}\right.$-value $\left.=0.50, \operatorname{RMSEA}=0.000\right), \operatorname{SSP}\left(\chi^{2}=7.19\right.$, $\mathrm{df}=9$, $\mathrm{p}$-value $=0.61$, RMSEA $=0.000)$, PIT $\left(\chi^{2}=3.34, \quad \mathrm{df}=7, \quad \mathrm{p}\right.$-value $=0.85$, RMSEA $=0.000)$, AIS $\quad\left(\chi^{2}=9.76, \mathrm{df}=11, \mathrm{p}-\right.$ value $=0.55$, RMSEA $\left.=0.000\right), \operatorname{CLS}\left(\chi^{2}=\right.$ 6.97, $\mathrm{df}=5, \mathrm{p}$-value $=0.22, \mathrm{RMSEA}=0.031), \operatorname{PRM}\left(\chi^{2}=19.58, \mathrm{df}=16, \quad \mathrm{p}\right.$-value $=0.24$, RMSEA $=0.023), \quad \operatorname{COD}\left(\chi^{2}=6.47, \quad \mathrm{df}=6, \quad \mathrm{p}\right.$-value $\left.=0.37, \quad \mathrm{RMSEA}=0.014\right), \quad$ and $\operatorname{MDC}\left(\chi^{2}=7.15, \mathrm{df}=8, \mathrm{p}\right.$-value $=0.52$, RMSEA $\left.=0.000\right)$. In accordance with the criteria of Jöreskog \& Sörbom, (1999) can be used to create a questionnaire to measure perception information and communication technology leadership.

Measurement of awareness of the importance of school administrators that need to have the information and communication technology leadership found that the school administrators gave importance to having information and communication technology leadership. School administrators who assume the roles of school directors, deputy school directors, heads of academic departments and heads of supporting sections have the perceptions of establishing a vision and guidelines for school work primarily concerned with ICT. School administrators who are equipped with a vision can inspire 
and develop their skills just like other school members (Gurr, Drysdale \& Mulford, 2006). They can determine strategies, encourage teachers and students to use technology for instruction and learning, and set plans to improve teachers' and staff's skills in technology so that they can work effectively with technology. Furthermore, they can manage, support, and facilitate the creation of an appropriate atmosphere, and allocate resources associated with IT, study challenges with care, and act as role models in applying technology to daily use pertaining to personal matters and professional aspects. Even though school directors may be effective and fine examples of how to plan and implement ICT for use by teachers and supporting staff, they are not necessarily experts in using ICT (Haughey, 2006), but need to give school teachers and staff knowledge and opportunities and establish a culture of ICT in order to shape learning communities.

\section{REFERENCES}

Akbaba-Altun, S. (2004). Information technology classrooms and elementary school principals' roles. Turkish experience. Education and Information Technologies, 9(3), 255-270.

Anderson, R. E., \& Dexter, S. L. (2005). School technology leadership: An empirical investigation of prevalence and effect. Educational Administration Quarterly, 41(1), 4982.

Anantha Raj A. Arokiasamya, Abdul Ghani Kanesan bin Abdullahb \& Aziah Ismailc. (2015). Correlation between cultural perceptions, leadership style and ICT usage by school principals in Malaysia. Procedia - Social and Behavioral Sciences, 176, 319332 .

Ayeni, A. A. (2004). Relevance of ICT to the construction of sports courts and pitches. West African Journal of Physical and Health Education, 8, 35-43.

Avery, S. (2014). The principal as Chief Learning Officer: Developing Teacher Leader."NASSP Bulletin.

Bishop, P. F. (2002). Information and Communication Technology and School Leaders. Paper presented at the Seventh World Conference on Computers in Education, Copenhagen.

Cusack, B., Gurr, D., \& Schiller, J. The impact of technology on the work of educational leaders, ACEL Hot Topic 1997 - 2003, 227 - 240.

David, Ng Foo Seong. (2011). How leadership for an ICT reform is distributed within a school. Policy and Leadership Studies, National Technological University, Singapore, and Jeanne Marie Ho Ministry of Education, Singapore.

Day, C., Harris, A., \& Hadfield, M. (2001). Challenging the orthodoxy of effective school leadership. International Journal leadership in Education, 4(1), 39-56.

DuFour, R., Eaker, R., \& Many, T. (2006). Learning by doing: A handbook for professional learning communities at work ${ }^{\mathrm{TM}}$. Bloomington, IN: Solution Tree. 
Geir, O. 2013. School Leadership for ICT and Teachers' Use of Digital Tools. Nordic Journal of Digital Literacy, 8, 107-125.

Gibson, I. W. (2002). PT3 and T3L-Teaching tomorrow's technology leaders: Preparing school leaders to use technology. Proceedings of SITE 2002: Society for Information Technology \& Teacher Education International Conference. Nashville, TN.

Gurr, D., Drysdale, L., \& Mulford, B. (2006). Models of successful principal leadership. School Leadership and Management, 26(4), 371 - 395.

Gurr, D. (2000). The impact of Information and Communication Technology on the Work of School Principals. Leading \& Managing, 6(1), 63 - 67.

Hair, J. F., Black, W. C., Bain, B. J., Anderson, R. E., \& Tatham, R. L. (2006).

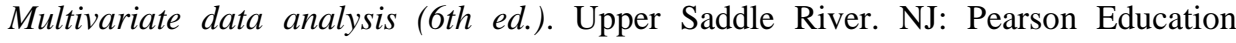
International.

Hately, N., \& Schiller, J. (2003) What personal ICT skills do school leaders need? The Practicing Administrator, 4, 5-7.

Haughey, M. (2006) The impact of computers on the work of the principal: changing discourses on talk, leadership and professionalism. School Leadership and Management. 26(1), 23 - 36.

Hope, W.C., Kelly, B., \& Guyden, J. (2000). Technology Standards for School Administrators: Implications for Administrator Preparation Programs. Paper presented at the Information Technology and Teacher Education Educational Conference, Sand Diego.

Januszewski, A., \& Molenda, M. (2008). Definition. In A. Januszewski \& M. Molenda (Eds.), Educational technology: A definition with commentary (1st. ed.). pp. 195-211. New York, US. Lawrence Earlbaum Associates.

Jöreskog, K. G., \& Sörbom, D. (1999). LISREL 8 User's Reference Guide. Lincolnwood, IL: Scientific Software International.

Kathryn, M. (2005). The Social Psychology of Organizations (2th ed.). New York: Wiley.

Kunsoo, H. (2013). Principal leadership for technology integration: A study of principal technology leadership. Doctoral dissertation, Drexel University.

Lee, M., Gaffney, M., \& Schiller, J. (2001). Integrating ICT in your school new opportunities for leadership. ACEL Hot Topic 1997 - 2003. 201 - 204.

Mark, G. (2007). ICT Leadership in School Education. A paper presented to the Australian Catholic University Conference "Directions for Catholic Education Leadership in the 21st Century". The Sofitel Wentworth Sydney, Australia. 
Mei Wei, Leong, Yan Piaw, Chua \& Kannan, Sathiamoorthy. (2017). Relationship between principal technology leadership practices and teacher ICT competency. Malaysian Online Journal of Educational Management, 4(3), 13-36.

Nwosu, A. A, (2003). Integrating ICT into STM Classroom: Status and Implications. Proceeding of the 44th Stan Conference 56 to 60.

Otto, T. L., \& Albion, P. R. (2002). Principals' confidence toward teaching with ICT: A critical element in leading appropriate change. Paper presented at Australian Computers in Education Conference, Hobart.

Redish, T., \& Chan, T. C. (2007). Technology Leadership: Aspiring Administrators' Perceptions of Their Leadership Preparation Program. Electronic Journal for the Integration of Technology in Education, 6, 123-139.

Schiller, J. (2000). Working with ICT: perceptions of Australian principals. Journal of Educational Administration, 41(2), 171-185.

Schiller, J. (2002). Surfers or Spectators? Principals and ICT. Principal Matters March $30-31$.

Schiller, J. (2003). Working with ICT Perceptions of Australian principals. Journal of Educational Administration, 41(2), 171-185.

Sultan A., \& Vian, A. (2015). Success factors for ICT implementation in Saudi secondary schools: From the perspective of ICT directors, head teachers, teachers and students. International Journal of Education and Development using ICT, 11(1): 36-54.

Sweeney, B. (2005). Management and Leadership in Schools. Teacher, August 48 50 .

Tabachnick, B. G., \& Fidell, L. S. (2007). Using Multivariate Statistics (5th ed.). New York: Allyn and Bacon.

Yee, B. (2000). Image of school principals' information and communication technology leadership. Journal of Information Technology for Teacher Education, 9(3), 287-302. 